Original article (short paper)

\title{
Step-count guidelines referenced on 60-minutes of moderate/vigorous physical activity
}

\author{
Fabio Eduardo Fontana \\ University of Northern Iowa, Cedar Falls, IA, USA \\ Michael Pereira da Silva \\ Federal University of Paraná, Curitiba, PR, Brazil \\ Ripley Marston \\ Kevin Finn \\ University of Northern Iowa, Cedar Falls, IA, USA \\ Jere Gallagher \\ University of Pittsburgh, Pittsburgh, PA, USA
}

\begin{abstract}
The purpose of this study was to establish step-count guidelines for sixth-grade students and assess the ability of step-counts to discriminate between students achieving and not achieving 60-minutes of moderate to vigorous physical activity daily. 201 sixth-grade students completed the study. They wore a pedometer and an accelerometer at the waist level for one full day. ROC curves were used to establish step-count guidelines and determine the diagnostic accuracy of step-counts. Sixth grade students need 12,118 steps/day to reach adequate daily levels of physical activity. The AUC indicated good diagnostic accuracy of step-counts. Suggested step-count guidelines can be a useful tool for identifying children who need to increase their daily levels of physical activity. The step-count cutoff proposed in this study is adequate for discriminating between sixth grade students reaching and not reaching recommended levels of physical activity.
\end{abstract}

Keywords: physical activity assessment; surveillance; exercise guidelines; step-count cutoff

Resumo - "Diretrizes de contagem de passos referenciadas em 60 minutos de atividade física de intensidade moderada e vigorosa." O objetivo deste estudo foi estabelecer diretrizes de passos por dia para estudantes da sexta série escolar e avaliar a possibilidade da contagem de passos para discriminar estudantes que atendem ou não a recomendação de 60 minutos diários de atividade física de moderada a vigorosa intensidade. 201 estudantes completaram o estudo. Ele usaram pedômetros e acelerômetros na cintura por 1 dia inteiro. Curvas ROC foram utilizadas para estabelecer diretrizes e precisão diagnóstica da contagem de passos. A AUC indicou boa capacidade diagnóstica da contagem de passos. Para atender níveis adequados de atividade física, 12.118 passos/dia são recomendados para estudantes da sexta série. Recomendações de contagem de passos sugeridas podem ser uma ferramenta útil para identificar crianças que necessitam aumentar seu nível diário de atividade física. O ponto de corte de passos/dia proposto neste estudo é adequado para discriminar estudantes de sexta série que atendem ou não níveis recomendados de atividade física.

Palavras-chave: avaliação de atividade física, monitoramento, recomendações de exercícios, pontos de corte de contagem de passos

Resumen - "Directrices de recuento de pasos referenciadas en 60 minutos de actividad física de intensidad moderada a vigorosa." El propósito de este estudio fue a establecerse directrices de pasos/día para los estudiantes de sexto grado y evaluar la capacidad de pasos/día para discriminar entre los estudiantes que alcanzan y no alcanzan 60 minutos de actividad física moderada a vigorosa. 201 estudiantes de sexto grado finalizaron el estudio. Ellos usaran un podómetro y un acelerómetro en el nivel de la cintura por un día completo. Se utilizaron curvas ROC para establecerse directrices y la exactitud diagnóstica de pasos/día. Para alcanzar un nivel adecuado de actividad física, se recomienda 12.118 pasos/día. El AUC mostró buena capacidad diagnóstica de pasos/día. Directrices de pasos/día sugeridos pueden ser una herramienta útil para la identificación de los niños que necesitan incrementar sus niveles de actividad física. El punto de corte de pasos/día propuesto es adecuado para discriminar entre los estudiantes que alcanzan y no alcanzan a los niveles recomendados de actividad física diario.

Palabras claves: evaluación de la actividad física; la vigilancia; recomendaciones de ejercicio; corte de pasos/día. 


\section{Introduction}

The increasing childhood obesity rate has intensified the focus on physical activity as a major public health initiative (Byrd-Williams et al., 2010; Miller, Rosenbloom, \& Silverstein, 2004; Moore et al., 2003). Identification of children with inadequate levels of physical activity is necessary for surveillance and screening purposes. Duration, frequency, and intensity of physical activity are the components of current physical activity guidelines. The U.S. Department of Health and Human Services (2008) recommends that children acquire a minimum of 60-minutes of moderate to vigorous aerobic physical activity daily. However, children, adolescents or their parents may not easily understand the existing guidelines. Recollection of physical activity duration and understanding of physical activity intensity are difficult tasks. Physical activity recall, a widely used procedure to assess physical activity behavior, is questionable since children and adolescents typically spread their activity throughout the day (Edmunds, Roche, \& Stratton, 2010). Besides, to objectively measure physical activity intensity and duration, expensive equipment (i.e. accelerometers, heart rate monitors) is necessary.

Pedometers are an attractive alternative to identifying children not reaching adequate levels of physical activity. Although they only provide a measure of total physical activity, pedometers are inexpensive, easy to use, and correlate strongly with accelerometry and heart rate monitoring (Tudor-Locke, Williams, Reis, \& Pluto, 2002). Pedometers have also been useful tools in physical activity interventions (Kang, Marshall, Barreira, \& Lee, 2009; Lubans, Morgan, \& Tudor-Locke, 2009; Schofield, Mummery, \& Schofield, 2005). Restructuring the current guidelines to step-counts can simplify physical acti- vity guidelines. Making physical activity guidelines a more viable resource for the assessment of physical activity habits may increase the adoption of step-count guidelines among physical activity interventionists for identifying whether children and adolescents are achieving recommended levels of physical activity.

Previous studies have established step-count guidelines for children (Table 1). However, the guidelines vary considerably (9,000-16,000 steps/day). The first study to propose step-count guidelines selected the cutoffs arbitrarily based on the mean steps achieved by the participants in the study (Vincent \& Pangrazi, 2002). The mean step-count of the sample tested may not correspond to adequate physical activity levels. A series of studies was conducted using BMI as the reference variable to determine step-count cutoffs (Laurson et al., 2008; McCormack, Rutherford, Giles-Corti, Tudor-Locke, \& Bull, 2011; Tudor-Locke et al., 2004), but BMI often misrepresents the weight problem of children due to its inability to account for maturation status and muscle mass (Nihiser et al., 2007). Duncan, Schofield, and Duncan (2007) improved upon the use of BMI by choosing body fat percentage as the criterion variable to select cutoffs, but neither BMI nor body fat are direct measures of physical activity behavior, and the correlation between body composition measures and physical activity behavior has generally been weak (Ribeiro et al., 2003; Wittmeier, Mollard, \& Kriellaars, 2008). Several of these studies also determined step-count cutoffs by multiples of 1,000 steps (Duncan et al., 2007; McCormack et al., 2011; Rowlands \& Eston, 2005; Tudor -Locke et al., 2004; Vincent \& Pangrazi, 2002), which may significantly misrepresent the assessment of physical activity habits (i.e. error $=+/-450$ steps/day).

Table 1. Step-count guidelines suggested across research studies.

\begin{tabular}{|c|c|c|c|c|}
\hline \multirow[b]{2}{*}{ Study } & \multicolumn{2}{|c|}{ Steps/day } & \multirow[b]{2}{*}{ Reference } & \multirow[b]{2}{*}{ Age } \\
\hline & Boys & Girls & & \\
\hline Adams et al. (2009) & 11,700 & 11,700 & Accelerometry & $11-16$ \\
\hline Adams et al. $(2013)^{\mathrm{a}}$ & 9,000 & 9,000 & Accelerometry & $6-17$ \\
\hline Colley et al. $(2012)^{\mathrm{a}}$ & 12,000 & 12,000 & Accelerometry & $6-19$ \\
\hline Duncan, Schofield, \& Duncan (2006) & 16,000 & 13,000 & Body Fat & $5-12$ \\
\hline Laurson et al. $(2008)^{\mathrm{a}}$ & 13,666 & 9,983 & BMI & $6-12$ \\
\hline McCormack et al. (2011) & 16,000 & 16,000 & BMI & $7-16$ \\
\hline Rowlands \& Eston (2005) & 13,000 & 12,000 & Accelerometry & $8-10$ \\
\hline Tudor-Locke, Johnson, \& Katzmarzyk (2010) & 15,000 & 12,000 & BMI & $6-12$ \\
\hline Vincent \& Pangrazi (2002) & 13,000 & 11,000 & Mean & $6-12$ \\
\hline
\end{tabular}

aThese studies suggested several different cutoff points. Adams et al. (2009) developed cutoffs for overweight adolescents only. The table indicates the cutoff based on the Freedson 4 METS equation, but they also suggested 10,000 steps/day based on the Freedson 3 METS equation. Adams et al. (2013) suggested specific cutoffs depending on the equation used to translate counts/min into moderate and vigorous physical activity (Freedson 3 and 4 METS, and Evenson), whether the step-counts measured via accelerometers were adapted to a pedometer scale, and two age groups (children $v s$. adolescents). The table indicates the cutoff based on the adaptation of uncensored step-counts cutoffs to pedometer counts. Colley et al. (2012) suggested 12,000 steps/day for simplicity of use, but their actual cutoffs ranged between 11,290 and 12,512 steps/day depending on age and sex of participants. The cutoffs proposed by Laurson et al. (2008) changed depending on the grouping of weight status (normal weight vs. overweight/obese; normal weight vs. obese; normal overweight vs. obese) and ROC cutoff selection procedure (i.e. matched cutpoint vs. ROC optimized). The steps/day in the table is for the comparison between normal weight vs. overweight/obese using the ROC optimized criterion. 
More recent studies referenced step-count cutoffs on 60-minutes of moderate to vigorous activity measured through accelerometry (Adams, Caparosa, Thompson, \& Norman, 2009; Adams, Johnson, \& Tudor-Locke, 2013; Colley, Janssen, \& Tremblay, 2012; Rowlands \& Eston, 2005). Step-count cutoffs proposed in two studies were based on small sample sizes (Adams et al., 2009; Rowlands \& Eston, 2005). Sample sizes in two other studies were large and representative (Adams et al., 2013; Colley et al., 2012). Colley et al. (2012) suggested 12,000 for Canadian boys and girls ages 6 to 19. However, similar to studies referencing step-count cutoffs on BMI (Duncan et al., 2007; Laurson et al., 2008; McCormack et al., 2011; Rowlands \& Eston, 2005; Tudor-Locke et al., 2004; Vincent \& Pangrazi, 2002), step-count guidelines were based on a sample with a broad developmental range, although children at different chronological ages show different physical activity habits (Troiano et al., 2008) and physical development levels (Malina, Bouchard, \& Bar-Or, 2004).

Studies basing cutoff decisions on the achievement of 60-minutes of moderate to vigorous physical activity generally used accelerometers to determine step-counts (Adams et al., 2013; Colley et al., 2012). Colley et al. (2012) used Actical accelerometers, but there is a lack of studies investigating how step-counts measured by Actical accelerometers translate into steps measured by research-quality pedometers (Adams et al., 2013). Adams et al. (2013) used Actigraph accelerometers, but Actigraph accelerometers and research-quality pedometers may produce discrepant step-counts. Daily step-counts measured by accelerometers seem to result in higher scores due to higher sensibility to detect low frequency physical activity (Masurier \& Tudor-Locke, 2003; McClain, Sisson, Washington, Craig, \& Tudor-Locke, 2007; Tudor-Locke, Ainsworth, Thompson, \& Matthews, 2002). Adams et al. (2013) proposed a step-count cutoff range of 11,500-13,500 steps/day for U.S. children and 11,500-14,000 steps/day for U.S. adolescents. Multiple techniques (i.e. Evenson and Age-specific Freedson 4 METS) and unadjusted accelerometer step-counts determined this range. To increase the applicability of guidelines, the authors offered a third cutoff of 9,000 steps/day for pedometer-determined steps based on the reduction of 2,500 steps from the lower end of the accelerometer unadjusted step-count guideline ranges (11,500 steps/day). Two-thousand and five-hundred steps were the estimated counts in low frequency physical activity $(<500$ counts/minute) based on investigations conducted using adult participants (Tudor-Locke, Johnson, \& Katzmarzyk, 2009, 2011). Additionally, the selection of the lower end of the suggested step-count ranges was arbitrary.

The purpose of this study was to establish step-count guidelines for sixth-grade students and assess the ability of step-counts to discriminate between students reaching and not reaching 60-minutes of moderate or higher physical activity daily. This project improved on the development of previous step-count guidelines by using pedometers to measure daily step-counts, recommending grade specific step-count cutoffs and proposing a single gendercombined step-count cutoff. Pedometers are more likely to be used to measure daily step-counts during interventions than accelerometers considering that accelerometers have the added advantage of estimating intensity of physical activity. Restricting the age span of participants to 11 and 12 year-olds allows for a sample of participants developmentally more homogeneous than samples used in some previous studies (Colley et al., 2012; Duncan et al., 2007; Laurson et al., 2008; McCormack et al., 2011; Tudor-Locke et al., 2004; Vincent \& Pangrazi, 2002). The use of accelerometry as the reference measure justifies the proposal of a single step-count cutoff for male and female students. It is common for accelerometry equations to be sex inclusive when determining physical activity intensity. This includes the age-specific Freedson 4 METS adopted in this paper (Troiano et al., 2008).

\section{Methods}

\section{Participants}

Two hundred and twenty-six sixth-grade students from three US-Midwest towns were invited to participate in the study. Two cities comprised a midsize urban center, and the third was an average size rural community. Sixth graders comprised the sample population due to evidence that physical activity levels start to show a more pronounced decline during this age period (Nader, Bradley, Houts, McRitchie, \& O'Brien, 2008; Troiano et al., 2008). We applied the following exclusion criteria during statistical analyzes to the data of participants who had: a. incomplete activity log; b. less than 10 hours of accelerometer wear (Troiano et al., 2008); c. equipment malfunction; d. age outside the typical range for sixth graders of 11- to 12-years of age. We obtained institutional review board approval (University of Northern Iowa, Approval number 09-0213, 3/8/2012), student written assent and parental written informed consent prior to the start of the study.

\section{Procedures}

We used Actigraph GT3X accelerometers and YAMAX SW-200 pedometers for data collection. Validity evidence strongly supporting the use of Actigraph accelerometers to estimate youth physical activity habits (Trost, Mciver, \& Pate, 2005), and YAMAX SW pedometers to count steps has been previously provided (Bassett et al., 1996; Crouter, Schneider, Karabulut, \& Bassett, 2003; Schneider, Crouter, Lukajic, \& Bassett, 2003). To ensure pedometer accuracy, before and after each data collection any instrument that failed the 100step test (+/- 2 steps) was eliminated. The ActiLife software (v4.4.1) computed the intensity level of accelerometer counts/ minute recorded for the vertical axis based on the age-specific Freedson 4 METS cut points (Freedson, Pober, \& Janz, 2005). Counts/minute cutoffs for 11 -year olds were $\leq 100$ counts $/ \mathrm{min}$ for sedentary, $>100$ counts/min for light, $\geq 2059$ for moderate, $\geq 4832$ for heavy, and $\geq 7605$ for very heavy physical activity. Counts/minute cutoffs for 12 -year olds were $\leq 100$ counts/min for sedentary, $>100$ counts/min for light, $\geq 2220$ for moderate, $\geq 5094$ for heavy, and $\geq 7956$ for very heavy physical activity.

Data collection started with a short training session provided at the school site, followed by height and weight measurements. 
Height was measured to the nearest centimeter $(\mathrm{cm})$ in stocking feet with the participant standing upright against a flexible, nonelastic anthropometric tape placed on a wall one hundred centimeters from the floor. A digital scale (Seca 770, Hamburg, Germany) measured weight to the nearest kilogram. BMI was calculated as weight $(\mathrm{kg}) /$ height $(\mathrm{m})^{2}$ and compared to CDC guidelines (Nihiser et al., 2007).

During training, participants were familiarized with the procedures of the study. Each participant received an activity log, a YAMAX SW-200 pedometer, and a GT3X Actigraph accelerometer. The pedometer and accelerometer were attached side by side to an elastic belt and positioned on the belt relative to the participant's dominant side of the body with the accelerometer closer to the center of the body. We taught participants how to put the belt on, so the devices were on the dominant side of the body. Participants were asked to wear them for one day during all waking hours except during any aquatic activity such as swimming or showering. More specifically, they were asked to, upon waking, put the belt on, reset the pedometer, and record the time on an activity log. At the end of the day, we asked participants to record on the activity log the number of steps taken during the day, the time the pedometer was removed, and whether either monitor was removed for more than 30 minutes throughout the day, along with the time and reason for removing it. Lastly, we asked students to return the pedometer, accelerometer, and activity log to the physical education office the day following data collection.

\section{Statistical analyses}

The participants were classified into adequate (minimum of 60 minutes of moderate/vigorous physical activity) and inadequate (less than 60 minutes of moderate/vigorous) levels of physical activity based on recommendations by the U.S. Department of Health and Human Services (2008). Subsequently, the Receiver Operating Characteristic (ROC) curve evaluated the diagnostic accuracy of pedometer step-counts and determined optimal step-count cutoffs using the two groups constructed based on accelerometry. Diagnostic accuracy, ability of step-counts to discriminate between adequate and inadequate levels of physical activity, was based on the area under the curve (AUC). Optimal cutoff points were set based on the Youden Index $(J=$ sensitivity + specificity -1$)$. The Youden index represents the farthest point on the ROC curve from chance (Akobeng, 2007). Sensitivity referred to the proportion of children with inadequate, and specificity to the proportion of children with adequate levels of physical activity, correctly classified by pedometer step-counts. We determined the optimal step-count cutoff for the overall sample of participants (boys and girls combined). For procedural check purposes, we also determined separate optimal step-count cutoffs for males and females. We conducted the statistical analyses using Analyse-it for Windows (v. 2.22).

\section{Results}

Of the 226 students who started the study, data for twentyfive participants were excluded from analysis $\left(\mathrm{N}_{\text {females }}=12\right.$; $\mathrm{N}_{\text {males }}=13$ ). Twelve participants did not return the activity log or returned incomplete logs, five wore accelerometers that malfunctioned, three wore the accelerometer for less than 10 hours, four students were older than 12-years of age, and one student was younger than 11-years of age. The remaining 201 participants constituted the sample used for statistical analyses. Table 2 describes the characteristics of the participants included in the data analyses.

Table 2. Demographic characteristics of participants included in data analysis $(n=201)$.

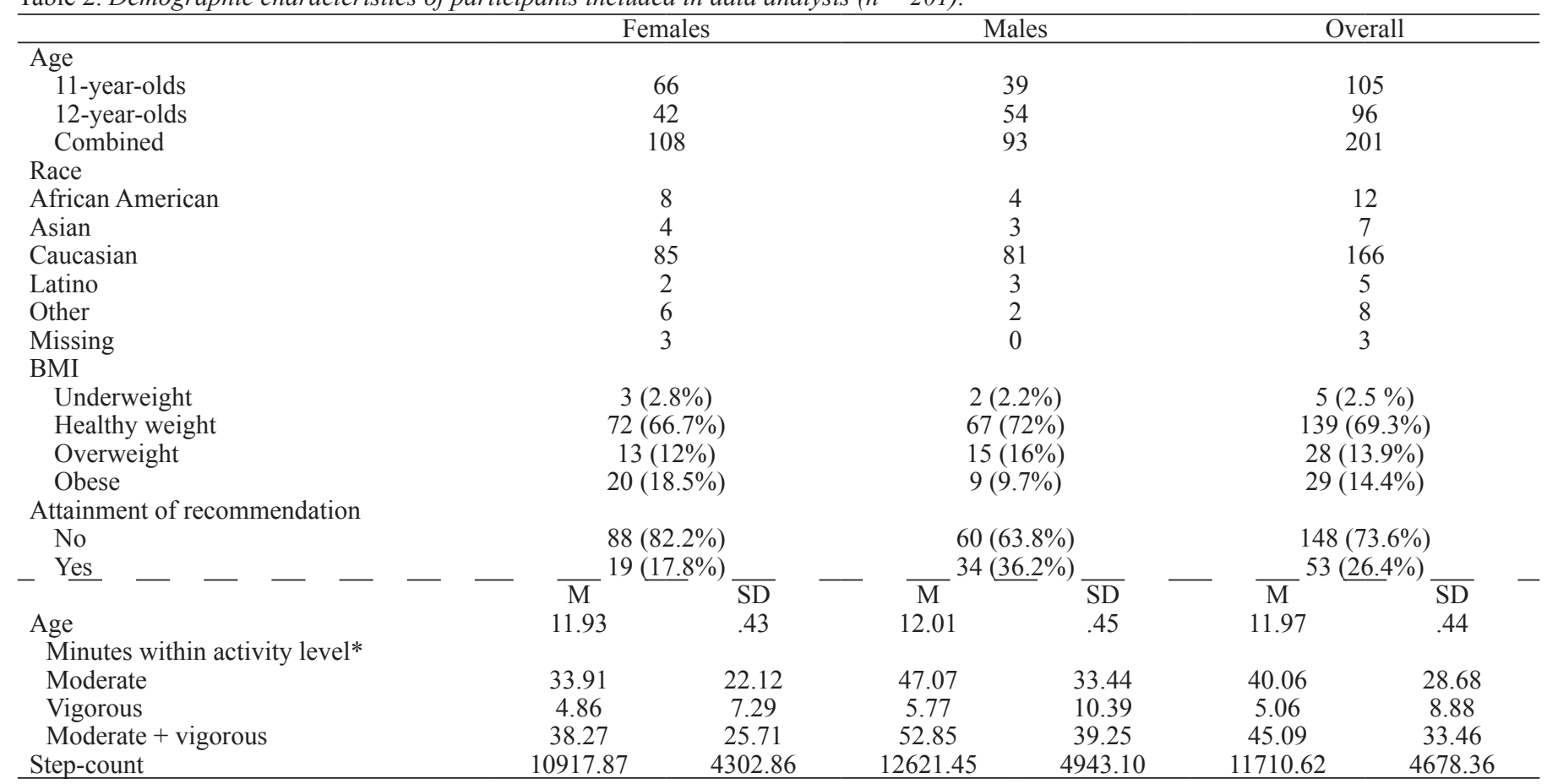

*Activity level was determined based on the Age-specific Freedson equation (4 METS). 
The AUC was equal to .85 for the overall sample of sixth grade students $(p<.01,95 \% \mathrm{CI}=.79-.9$; Figure 1$), .88$ for males $(p<.01,95 \% \mathrm{CI}=.81-.95)$, and .80 for females $(p<$ $.01,95 \% \mathrm{CI}=.81-.95)$. The optimal step-count cutoff point for the overall sample of sixth grade students was equal to 12,118 steps/day (Table 3 ). Sex specific cutoffs were respectively 12,118 and 12,605 steps/day for males and female sixth grade students.

Table 3. Sensitive and specificity scores across sex-combined stepcount cutoff points.

\begin{tabular}{|c|c|c|c|}
\hline Step-count cutoff & Sensitivity & Specificity & Youden index \\
\hline 1332 & 0.0 & 1.0 & 0.0 \\
\hline 1833 & .007 & 1.0 & .007 \\
\hline 3018 & .014 & 1.0 & .014 \\
\hline 3635 & .020 & 1.0 & .020 \\
\hline 4263 & .027 & 1.0 & .027 \\
\hline \multicolumn{4}{|l|}{$\ldots$} \\
\hline 11186 & .703 & .868 & .571 \\
\hline 11219 & .709 & .868 & .577 \\
\hline 11222 & .716 & .868 & .584 \\
\hline 11304 & .723 & .868 & .591 \\
\hline 11425 & .730 & .868 & .598 \\
\hline 11436 & .736 & .868 & .604 \\
\hline 11563 & .743 & .868 & .611 \\
\hline 11580 & .750 & .868 & .618 \\
\hline 11613 & .750 & .849 & .599 \\
\hline 11987 & .757 & .849 & .606 \\
\hline 12070 & .764 & .849 & .613 \\
\hline 12088 & .770 & .849 & .619 \\
\hline 12118 & .777 & .849 & .626 \\
\hline 12130 & .777 & .830 & .607 \\
\hline 12201 & .784 & .830 & .614 \\
\hline 12504 & .784 & .811 & .595 \\
\hline 12536 & .791 & .811 & .602 \\
\hline 12605 & .797 & .811 & .609 \\
\hline 12633 & .797 & .792 & .590 \\
\hline 12642 & .804 & .792 & .597 \\
\hline 12825 & .811 & .792 & .603 \\
\hline 12890 & .811 & .774 & .584 \\
\hline 13067 & .818 & .774 & .591 \\
\hline 13074 & .824 & .774 & .598 \\
\hline 13094 & .824 & .755 & .579 \\
\hline 13096 & .824 & .736 & .560 \\
\hline 11186 & .703 & .868 & .571 \\
\hline \multicolumn{4}{|l|}{$\ldots$} \\
\hline 23020 & .986 & .057 & .043 \\
\hline 24026 & .993 & .057 & .050 \\
\hline 24677 & .993 & .038 & .031 \\
\hline 27562 & .993 & .019 & .012 \\
\hline 30000 & 1.0 & .019 & .019 \\
\hline
\end{tabular}

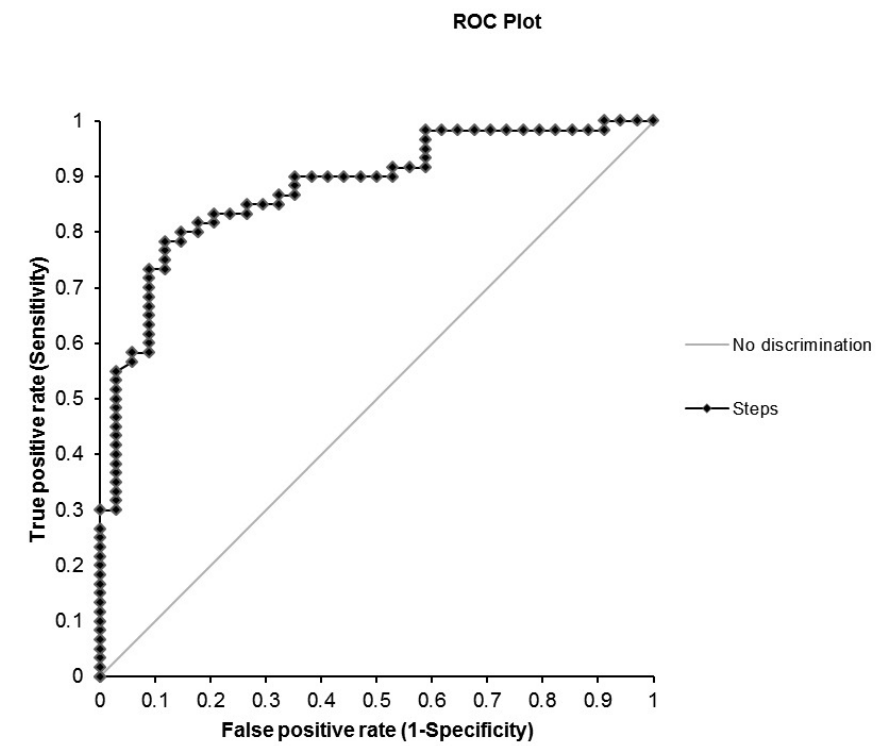

Figure 1. ROC curves for step-counts $(A U C=.85)$.

\section{Discussion}

Identifying children not reaching adequate levels of physical activity may help parents, teachers, and health professionals be more proactive about physical activity. The U.S. Department of Health and Human Services (2008) recommends a minimum of 60-minutes of moderate to vigorous physical activity daily. However, intensity is not easily understood and duration is difficult to recall by children and adolescents (Goodman, Daniels, Meigs, \& Dolan, 2007; Sallis, Buono, Roby, Micale, \& Nelson, 1993). This paper restructured the guidelines based on duration and intensity of physical activity to reflect step-counts. The 12,118 steps/day guideline is a useful framework to determine whether 11 and 12 year-old children are reaching adequate levels of physical activity, so changes to physical activity habits can be implemented when necessary.

We proposed a single step-count cutoff that was independent of sex due to the use of the Age-specific Freedson 4 METS procedure to estimate physical activity intensity. The counts/minute cutoffs associated with different physical activity intensities under this equation are the same regardless of the sex of participants. The results of this study also provide support for the selection of a single step-count cutoff point. The overall step-count cutoff $(12,118 \mathrm{steps} /$ day) was remarkably similar to the sex-specific cutoffs for males (12,118 steps/day) and females (12,605 steps/ day). In the study, boys and girls participated in similar proportions of moderate and vigorous physical activity. Out of the overall participation in activity equal or above moderate levels, boys and girls spent $89.06 \%$ and $88.61 \%$ on moderate and $10.92 \%$ and $11.39 \%$ in vigorous physical activity respectively. Finally, other studies using accelerometry have also suggested a single step-count cutoff for males and females. Adams et al. (2009) developed a single step-count cutoff for overweight boys and girls. Adams et al. (2013) and Colley et al. (2012) developed separate cut points for boys and girls, but suggested a single cutoff due to how similar the cutoffs were for both sexes. 
Comparison of step-count guidelines suggested by this study to guidelines proposed in past studies (Duncan et al., 2007; Laurson et al., 2008; McCormack et al., 2011; Rowlands \& Eston, 2005; Tudor-Locke et al., 2004; Vincent \& Pangrazi, 2002) is compromised by the use of different methodologies. Compared to the studies using BMI as the reference criterion, the step-count cutoffs proposed here are lower than previously proposed guidelines for boys, and similar to guidelines proposed for girls (Table 1). Interestingly, cutoffs suggested in this paper are remarkably similar to the cutoff suggested by other studies using accelerometry as the reference criterion (Adams et al., 2009; Colley et al., 2012; Rowlands \& Eston, 2005). The recommendation made by this paper was within the range of accelerometer measured steps/day recommended by Adams et al. (2013), but lower than the pedometer scaled steps/day made by the same authors. The pedometer scaling procedure used by Adams et al. (2013) was developed for adults (Tudor-Locke et al., 2009, 2011), and may need to be subjected to additional testing using an array of different brands of accelerometers and pedometers. Previous accelerometry-based studies reinforce the use of 12,118 steps/day to discriminate among sixth-grade students achieving and not achieving 60-minutes of moderate to vigorous physical activity daily.

The use of step-count guidelines to identify whether children are reaching physical activity recommendations will produce misclassifications. Pedometer step-counts are indirect measures of physical activity duration and intensity and do not measure non-locomotor forms of physical activity such as swimming and biking. The fact that step-count guidelines in this study showed good ability to discriminate among sixth-grade students reaching and not reaching 60-minutes of accelerometer determined daily moderate to vigorous physical activity (AUC $\mathrm{Averall}_{\text {}}$ $=.85$ ) is worth noting. Not only did step-count guidelines adequately differentiate between children with adequate and inadequate levels of physical activity, but they were also a convenient strategy in the assessment of physical activity habits in children. Pedometers are inexpensive, and their output is simple to understand (Tudor-Locke, Williams, Reis, \& Pluto, 2002). Thus, we recommend the use of 12,118 steps/day as an important initial epidemiological step to identify children with low levels of physical activity.

Future studies on this topic should focus on the development of age-specific guidelines for a broader developmental spectrum. Due to differences in physical development (Malina et al., 2004) and physical activity habits (Nader et al., 2008; Troiano et al., 2008), developing age-specific guidelines may be necessary for improving the accuracy of step-count cutoff points. A table of cutoff points by chronological age can simplify the use of stepcount recommendations by parents, school, and professionals dealing with pediatric populations.

This study is not without limitations. The participants were selected exclusively from the Midwest, and the ethnic proportions in the US population were not adequately represented. In addition, accelerometry is not a gold standard to classify physical activity levels, and different equations can produce different cutoff points. However, a measure of physical activity levels that contains no error does not currently exist. In fact, we believe a strength of the paper was the use of the Freedson age-specific 4 METS as a single procedure to determine physical activity intensity. Adams et al. (2013) suggested separate step-count cutoff ranges for children and adolescents developed based on different procedures of assigning intensity to counts/ min (Evenson and Freedson age-specific 3 and 4 METs). Without a consensus about the best equation to estimate physical activity intensity, there are advantages to suggesting a range of step-count cutoff points. However, the use of a range may undermine the applicability of step-count cutoffs in physical activity interventions. Requiring parents, schools, and professionals dealing with pediatric populations to select the optimal point within a range of cutoff points may not be realistic. Hence, the researchers of this study opted to develop a single step-count cutoff point for sixth-grade students based on a well-accepted youth equation to determine moderate to vigorous physical activity. Several previous studies recommended the use of the Freedson age-specific 4 METs for the determination of youth physical activity (Adams et al., 2013; Mattocks et al., 2007; Treuth et al., 2004; Troiano et al., 2008).

Using pedometers to measure steps directly in normative studies may be another advantage of this paper. Studies employing similar methodological procedures decided for the use of accelerometers to measure daily steps (Adams et al., 2009, 2013; Colley et al., 2012). Accelerometer and pedometer stepcounts may not be congruent. In fact, a well-designed study by Adams et al. (2013) suggested a pedometer friendly version of their accelerometer developed step-count cutoff to increase the practically of their step-count recommendation. This pedometer friendly version did not count steps taken below a threshold of 500 counts/min. Previous studies have suggested that accelerometers are more sensitive to count steps in low frequency. However, the choice of frequency was determined using adult participants (Tudor-Locke et al., 2009, 2011). In any case, using pedometers to measure daily steps in studies developing step-count guidelines seems more appropriate than basing step-counts on accelerometer readings. Interventionists are less likely to use accelerometers, which measure frequency, duration and intensity of physical activity, to estimate physical activity behavior. The use of the more practical and inexpensive pedometers to develop step-count cutoffs is expected to improve the generalizability of the proposed step-count guidelines to physical activity interventions.

It is common for studies measuring physical activity habits to recommend a minimum of four days of physical activity monitoring (Tudor-Locke, Ainsworth, et al., 2002). However, it is important to emphasize that the concern of this project is not with the description of the physical habits of the participants. Thus, frequency of physical activity is not an important variable for the study. This study focused exclusively on the duration and intensity of physical activity recommendations suggested by the U.S Department of Health and Human Services (2008). One day of measurement was appropriate for the identification of step-counts corresponding to the accumulation of 60-minutes of moderate or higher physical activity, and it has been replicated previously (Adams et al., 2013; Tudor-Locke et al., 2009). 


\section{References}

Adams, M. A., Caparosa, S., Thompson, S., \& Norman, G. J. (2009). Translating physical activity recommendations for overweight adolescents to steps per day. Preventive Medicine, 37, 137-140. doi:10.1016/j.amepre.2009.03.016

Adams, M. A., Johnson, W. D., \& Tudor-Locke, C. (2013). Steps/ day translation of the moderate-to-vigorous physical activity guideline for children and adolescents. International Journal of Behavioral Nutrition and Physical Activity., 10, 49. doi:10.1186/1479-5868-10-49

Akobeng, A. K. (2007). Understanding diagnostic tests 3: Receiver operating characteristic curves. Acta Paediatrica, 96, 644-647. doi:10.1111/j.1651-2227.2006.00178.x

Bassett, D. R., Ainsworth, B. E., Leggett, S. R., Mathien, C. A., Main, J. A., Hunter, D. C., \& Duncan, G. E. (1996). Accuracy of five electronic pedometers for measuring distance walked. Medicine and Science in Sports and Exercise, 28, 1071-1077.

Byrd-Williams, C. E., Belcher, B. R., Spruijt-Metz, D., Davis, J. N., Ventura, E. E., Kelly, L., ... Goran, M. I. (2010). Increased physical activity and reduced adiposity in overweight Hispanic adolescents. Medicine and Science in Sports and Exercise, 42, 478-484. doi:10.1249/MSS.0b013e3181b9c45b

Colley, R. C., Janssen, I., \& Tremblay, M. S. (2012). Daily step target to measure adherence to physical activity guidelines in children. Medicine and Science in Sports and Exercise, 44, 977-982. doi:10.1249/MSS.0b013e31823f23b1

Crouter, S. E., Schneider, P. L., Karabulut, M., \& Bassett, D. R. (2003). Validity of 10 electronic pedometers for measuring steps, distance, and energy cost. Medicine and Science in Sports and Exercise, 35, 1455-1460. doi:10.1249/01.MSS.0000078932.61440.A2

Duncan, J. S., Schofield, G., \& Duncan, E. K. (2006). Pedometerdetermined physical activity and body composition in New Zealand children. Medicine and Science in Sports and Exercise, 38, 1402-1409. doi:10.1249/01.mss.0000227535.36046.97

Duncan, J. S., Schofield, G., \& Duncan, E. K. (2007). Step count recommendations for children based on body fat. Preventve Medicine, 44, 42-44. doi:10.1016/j.ypmed.2006.08.009

Edmunds, S., Roche, D., \& Stratton, G. (2010). Levels and patterns of physical activity in children and adolescents with type 1 diabetes and associated metabolic and physiologic health outcomes. Journal of Physical Activity and Health, 7, 68-77.

Freedson, P., Pober, D., \& Janz, K. F. (2005). Calibration of Accelerometer Output for Children. Medicine and Science in Sports and Exercise, 37(Supplement), S523-S530. doi:10.1249/01. mss.0000185658.28284.ba

Goodman, E., Daniels, S.R., Meigs, J.B., \& Dolan, L.M. (2007). Instability in the diagnosis of metabolic syndrome in adolescents. Circulation, 115, 2316-2322. doi:10.1161/CIRCULATIONAHA.106.669994.

Kang, M., Marshall, S. J., Barreira, T. V, \& Lee, J.-O. (2009). Effect of pedometer-based physical activity interventions: a meta-analysis. Research Quaterly for Exercise and Sport, 80, 648-655.

Laurson, K. R., Eisenmann, J. C., Welk, G. J., Wickel, E. E., Gentile, D. A., \& Walsh, D. A. (2008). Evaluation of youth pedometer-determined physical activity guidelines using receiver operator characteristic curves. Preventive Medicine, 46, 419-424. doi:10.1016/j. ypmed.2007.12.017

Lubans, D. R., Morgan, P. J., \& Tudor-Locke, C. (2009). A systematic review of studies using pedometers to promote physical activity among youth. Preventive Medicine, 48, 307-315. doi:10.1016/j. ypmed.2009.02.014

Malina, R. M., Bouchard, C., \& Bar-Or, O. (2004). Growth, matu- ration, and physical activity (2nd ed., p. 712). Champaign, IL: Human Kinetics.

Masurier, G. C. L., \& Tudor-Locke, C. (2003). Comparison of pedometer and accelerometer accuracy under controlled conditions. Medicine and Science in Sports and Exercise, 35, 867-871. doi:10.1249/01.MSS.0000064996.63632.10

Mattocks, C., Leary, S., Ness, A., Deere, K., Saunders, J., Tilling, K., ... Riddoch, C. (2007). Calibration of an accelerometer during free-living activities in children. International Journal of Pediatric Obesity, 2, 218-226. doi:10.1080/17477160701408809

McClain, J. J., Sisson, S. B., Washington, T. L., Craig, C. L., \& Tudor-Locke, C. (2007). Comparison of Kenz Lifecorder EX and ActiGraph accelerometers in 10-yr-old children. Medicine and Science in Sports and Exercise, 39, 630-638. doi:10.1249/ mss.0b013e3180313056

McCormack, G. R., Rutherford, J., Giles-Corti, B., Tudor-Locke, C., \& Bull, F. (2011). BMI-referenced cut-points for recommended daily pedometer-determined steps in Australian children and adolescents. Research Quaterly for Exercise and Sport, 82, 162-167.

Miller, J., Rosenbloom, A., \& Silverstein, J. (2004). Childhood obesity. Journal of Clinical Endocrinology and Metabolism, 89, 4211-4218. doi:10.1210/jc.2004-0284

Moore, L. L., Gao, D., Bradlee, M. L., Cupples, L. A., Sundarajan-Ramamurti, A., Proctor, M. H., ... Ellison, R. C. (2003). Does early physical activity predict body fat change throughout childhood? Preventive Medicine, 37, 10-17.

Nader, P. R., Bradley, R. H., Houts, R. M., McRitchie, S. L., \& O’Brien, M. (2008). Moderate-to-vigorous physical activity from ages 9 to 15 years. JAMA, 300, 295-305. doi:10.1001/jama.300.3.295

Nihiser, A. J., Lee, S. M., Wechsler, H., McKenna, M., Odom, E., Reinold, C., ... Grummer-Strawn, L. (2007). Body mass index measurement in schools. Journal of School Health, 77, 651-671; quiz 722-4. doi:10.1111/j.1746-1561.2007.00249.x

Ribeiro, J., Guerra, S., Pinto, A., Oliveira, J., Duarte, J., \& Mota, J. (2003). Overweight and obesity in children and adolescents: relationship with blood pressure, and physical activity. Annals of Human Biology, 30, 203-213.

Rowlands, A. V, \& Eston, R. G. (2005). Comparison of accelerometer and pedometer measures of physical activity in boys and girls, ages 8-10 years. Research Quaterly for Exercise and Sport, 76, 251-257.

Sallis JF, Buono MJ, Roby JJ, Micale FG, Nelson JA. (1993). Seven-day recall and other physical activity self-reports in children and adolescents. Medicine and Science in Sports and Exercise, 25, 99-108.

Schneider, P. L., Crouter, S. E., Lukajic, O., \& Bassett, D. R. (2003). Accuracy and reliability of 10 pedometers for measuring steps over a 400-m walk. Medicine and Science in Sports and Exercise, 35, 1779-1784. doi:10.1249/01.MSS.0000089342.96098.C4

Schofield, L., Mummery, W. K., \& Schofield, G. (2005). Effects of a controlled pedometer-intervention trial for low-active adolescent girls. Medicine and Science in Sports and Exercise, 37, 1414-1420.

Treuth, M. S., Schmitz, K., Catellier, D. J., McMurray, R. G., Murray, D. M., Almeida, M. J., ... Pate, R. (2004). Defining accelerometer thresholds for activity intensities in adolescent girls. Medicine and Science in Sports and Exercise, 36, 1259-1266.

Troiano, R. P., Berrigan, D., Dodd, K. W., Mâsse, L. C., Tilert, T., \& McDowell, M. (2008). Physical activity in the United States measured by accelerometer. Medicine and Science in Sports and Exercise, 40, 181-188. doi:10.1249/mss.0b013e31815a51b3

Trost, S. G., Mciver, K. L., \& Pate, R. R. (2005). Conducting Accelerometer-Based Activity Assessments in Field-Based Research. Medicine and Science in Sports and Exercise, 37(Supplement), S531-S543. doi:10.1249/01.mss.0000185657.86065.98 
Tudor-Locke, C., Ainsworth, B. E., Thompson, R. W., \& Matthews, C. E. (2002). Comparison of pedometer and accelerometer measures of free-living physical activity. Medicine and Science in Sports and Exercise, 34, 2045-2051. doi:10.1249/01. MSS.0000039300.76400.16

Tudor-Locke, C., Johnson, W. D., \& Katzmarzyk, P. T. (2009). Accelerometer-determined steps per day in US adults. Medicine and Science in Sports and Exercise, 41, 1384-1391. doi:10.1249/ MSS.0b013e318199885c

Tudor-Locke, C., Johnson, W. D., \& Katzmarzyk, P. T. (2010). Accelerometer-determined steps per day in US children and youth. Medicine and Science in Sports and Exercise,42, 2244-2250. doi:10.1249/MSS.0b013e3181e32d7f

Tudor-Locke, C., Johnson, W. D., \& Katzmarzyk, P. T. (2011). Relationship between accelerometer-determined steps/day and other accelerometer outputs in US adults. Jorunal of Physical Activity and Health., 8, 410-419.

Tudor-Locke, C., Pangrazi, R. P., Corbin, C. B., Rutherford, W. J., Vincent, S. D., Raustorp, A., ... Cuddihy, T. F. (2004). BMI-referenced standards for recommended pedometer-determined steps/ day in children. Preventive Medicine, 38, 857-864. doi:10.1016/j. ypmed.2003.12.018

Tudor-Locke, C., Williams, J. E., Reis, J. P., \& Pluto, D. (2002). Utility of pedometers for assessing physical activity: convergent validity. Sports Medicine, 32, 795-808.

U.S. Department of Health and Human Services. (2008). 2008 Physical Activity Guidelines for Americans. Washington, DC. Retrieved from http://www.health.gov/paguidelines/guidelines/chapter3.aspx

Vincent, S. D., \& Pangrazi, R. P. (2002). An examination of the activity patterns of elementary school children. Pediatric Exercise Science, 14, 4320441.

Wittmeier, K. D. M., Mollard, R. C., \& Kriellaars, D. J. (2008). Physical activity intensity and risk of overweight and adiposity in children. Obesity (Silver Spring), 16, 415-420. doi:10.1038/oby.2007.73

\section{Authors' note}

Fabio Eduardo Fontana, Ripley Marston, and Kevin Finn are affiliated with the School of Health, Physical Education, and Leisure Services, University of Northern Iowa, Cedar Falls, IA, USA.

Michael Pereira da Silva is affiliated with the Center for Exercise and Sports, Federal University of Parana, Curitiba, Brazil.

Jere Gallagher is affiliated with the Health and Physical Activity Department, University of Pittsburgh, Pittsburgh, PA, USA.

\section{Corresponding author}

Fabio Fontana

School of Health, Physical Education, and Leisure Services, University of Northern Iowa, 203 Wellness/Recreation Center, Cedar Falls, IA 50614, USA, phone (319) 273-6854, fax (319) 273-5958, e-mail fabio.fontana@uni.edu

\section{Acknowledgments}

This study was supported by a faculty fellowship award from the University of Northern Iowa.

The authors have no conflict of interest to declare.

\section{Conflict of interest}

The authors declare that they have no conflict of interest.

Manuscript received on October 18, 2013

Manuscript accepted on December 16, 2014

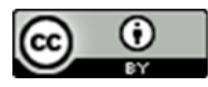

Motriz. The Journal of Physical Education. UNESP. Rio Claro, SP, Brazil - eISSN: 1980-6574 - under a license Creative Commons - Version 3.0 